\title{
Raven food calls indicate sender's age and sex
}

\author{
Markus Boeckle ${ }^{1,2,3^{*}}$ (D), Georgine Szipl ${ }^{1,2}$ and Thomas Bugnyar ${ }^{1,2}$
}

\begin{abstract}
Background: Acoustic parameters of animal signals have been shown to correlate with various phenotypic characteristics of the sender. These acoustic characteristics can be learned and categorized and thus are a basis for perceivers' recognition abilities. One of the most demanding capacities is individual recognition, achievable only after repeated interactions with the same individual. Still, class-level recognition might be potentially important to perceivers who have not previously encountered callers but can classify unknown individuals according to the already learned categories. Especially for species with high fission-fusion dynamics that repeatedly encounter unknown individuals it may be advantageous to develop class-level recognition. We tested whether frequency-, temporal-, and amplitude-related acoustic parameters of vocalizations emitted by ravens, a species showing high fission-fusion dynamics in non-breeder aggregations, are connected to phenotypic characteristics and thus have the potential for class-level recognition.

Results: The analysis of 418 food calls revealed that some components summarizing acoustic parameters were differentiated by age-classes and sex.

Conclusions: Together, the results provide evidence for the co-variation of vocal characteristics and respective sex and age categories, a prerequisite for class-level recognition in perceivers. Perceivers that are ignorant of the caller's identity can thus potentially recognize these class-level differences for decision-making processes in feeding contexts.
\end{abstract}

Keywords: Corvus corax, Raven, Food call, Sex, Age, Call production, Vocalization, Acoustic characteristics, Bioacoustics, Corvid

\section{Background}

Territorial defence and parent-offspring are two well-studied contexts in which individual recognition is important [1-3], as individuals can benefit from memorizing the identity of the individuals as well as the type and/or outcome of previous interactions [4]. In species where individuals meet regularly after prolonged times, such as in fission-fusion systems [5], individual recognition based on acoustic communication appears highly beneficial $[1,5]$. Still, in species with a high degree of fission-fusion dynamics, a large number of individuals within fluid groups, and large home-ranges, individuals might not only encounter known individuals but also unknown ones, for which no

\footnotetext{
* Correspondence: markus.boeckle@gmail.com

${ }^{1}$ Department of Cognitive Biology, University of Vienna, Vienna, Austria

${ }^{2}$ Konrad Lorenz Forschungsstelle, Core Facility, University of Vienna, Gruenau im Almtal, Austria

Full list of author information is available at the end of the article
}

memory about previous interactions or information about their identity is available. During encounters with unknown individuals individual recognition is not possible, while class-level recognition can provide crucial benefits [1].

Vocal signals may convey various attributes of the vocalizer, among others sex (e.g.: [6]), age (e.g.: [7]), emotional state (e.g.: [8]), dominance rank hierarchy (e.g.: [9]), and reproductive status (e.g.: [10]). How and which of these attributes are obtained by perceivers from acoustic signals has been extensively studied in the last decades (e.g. [2]). Most of the acoustic parameters in focus relate to anatomical features of the producer and its production mechanisms. Fant [11] suggested that vocal production in humans is a two-stage process: vocalizations are produced by the vibrating tissue, and subsequently shaped by the vocal tract. This "source-filter theory" has successfully been generalized [12] to other mammals [13, 14], and also to birds [15-18]. In some species, vocal features such as fundamental frequency, frequency modulation, and other 
source dependent characteristics provide dependable cues to body size but also to genetic variation and age $[19,20]$.

In corvids like common ravens (Corvus corax), anatomic size differences between sexes and age groups are hypothesized to directly relate to acoustic parameters of the calls [21-25], providing cues to class-level recognition. Sex and age dependencies of acoustic signals in ravens might be similar to other bird species $[26,27]$ and seem linked to size differences between sexes and age-classes [28, 29]. Moreover, class-level distinction between sexes and age-classes that are based on acoustic features could be exploited by conspecifics for various forms of decision-making. In ravens, acoustic information about sex and age-class could be useful especially when encountering unknown individuals while deciding whether to engage in territorial defence or to join or avoid foraging groups [30-32]. Unlike features that are connected to caller identity [33], acoustic features related to sex, and age might not have to be learned of each single individual as cues to class-level recognition [1]. This is especially interesting in foraging ravens due to their fission-fusion dynamics [34-36]. Individuals gather at large and ephemeral carcasses, where they may encounter familiar and unfamiliar birds [37-41].

Ravens facing problems in accessing food are hypothesized to recruit conspecifics via vocalizations in order to reduce potential dangers and to overpower dominant conspecifics during feeding [30,31, 37-41]. These food related calls, often referred to as 'yells' or long 'haa' calls $[38,40]$ are individually distinct [33]. While ravens were shown to discriminate between known and unknown individuals of different sexes, indicating class-level recognition [30], age-related differences in 'haa' calls have not been investigated, yet. Moreover, different age-classes have been described to differ in their food call characteristics [37, 40], but in-depth analysis of acoustic features is still missing. 'Haa' calls show highly harmonic structures in addition to non-linear phenomena in some calls. Resonance frequencies produced by the vocal tract, named formants, cannot be measured because of the highly harmonic structure of the calls as well as the fact that fundamental frequency and its harmonics differ around $800 \mathrm{~Hz}$ [33]. Due to large frequency ranges with no or low amplitude, any attributes in raven 'haa' calls that might indicate sex and age are primarily based on source related production mechanisms (i.e. fundamental frequency). We here investigate the variation of 'haa' call characteristics of common ravens related to age-classes and sex. We predict that in addition to previously described individual characteristics, age and sex differences are detectable in the food-related 'haa' call based on anatomical differences and potential variations in production mechanisms. In a society with high fission-fusion dynamics, known individuals might be recognized via individually distinct cues, while unknown callers could be classified according to age-class and sex, thereby assessing the degree of competition. Differentiating unknown individuals according to these class-specific cues can aid in decision-making processes, i.e. whether to approach or to retreat from an unfamiliar recruiting caller.

\section{Methods}

\section{Study site and call recording}

Between summer 2009 and winter 2010 we recorded 'haa' calls of free-ranging common ravens that regularly forage inside the enclosures of the Cumberland Wildpark Grünau, Austria [42]. At the time of the study, approximately 100 ravens were marked individually with coloured leg bands and patagial wing tags. Individual information of these birds (e.g. weight, sex and age-class) was known [43]. Sex was genetically determined from blood samples (Laboklin, Austria). Age-classes were classified based on the coloration of the feathers and the inner beak: juveniles from fledging until the end of their first year have mostly pink oral cavities and brownish feathers; in subadults in their second and third year of life oral cavities turn from pink to black, i.e. are pinkish with dark speckles, and adults ( $>3$ years) have black oral cavities [44, 45]. The spectrograms in Fig. 1 show examples of 'haa' calls of each age-class.

We recorded calls of individually marked ravens between $0700 \mathrm{~h}$ and $0900 \mathrm{~h}$ at the feedings of wild boars (Sus scrofa), where ravens gather for foraging on a daily basis. We simultaneously video- and audio-recorded each feeding session to identify vocalizing individuals (Video-recorder: Canon HF-11 HD; microphone: Sennheiser ME67/ K6; solid-state audio-recorder: Marantz PMD-670: sampling rate $=48 \mathrm{kHz}$, amplitude resolution $=16$ bits) at distances ranging from 3 to $10 \mathrm{~m}$. All calls with interfering background noise were removed. Additionally, we removed two individuals (two subadult males) represented with only one call each from the dataset, which provided us with 418 calls of 12 individuals (mean number of call per individual $\pm \mathrm{SD}=34.83 \pm 34.51$; 3 juveniles: 1 male(m), 2 females (f); 7 subadults: $2 \mathrm{~m}, 5 \mathrm{f} ; 7$ adults: $1 \mathrm{~m}, 6 \mathrm{f}$ ).

\section{Call analysis}

Acoustic analysis was conducted using a script in PRAAT 5.1.25 [46] that automatically logged acoustic variables in an output file. Because of the highly harmonic structure of the 'haa' call we mainly used source related acoustic features that are related to fundamental frequency $(f o)$ using recently suggested terminology for acoustic measurements [47]. The analysed call parameters were mean $f_{\mathrm{O}}(\mathrm{Hz})$, maximum $f_{\mathrm{O}}\left(\max f_{\mathrm{o}} ; \mathrm{Hz}\right), \operatorname{minimum} f_{\mathrm{O}}\left(\min f_{\mathrm{o}}\right.$; $\mathrm{Hz}$ ), range of $f_{\mathrm{o}}(\mathrm{Hz})$, start $f_{\mathrm{o}}(\mathrm{Hz})$, end $f_{\mathrm{o}}(\mathrm{Hz}), f_{\mathrm{O}}$ at the half of call duration (mid $f_{\mathrm{o}} ; \mathrm{Hz}$ ), call duration (s), slope from $f_{0}$ start of the call to the fo maximum (slope S-M; $\mathrm{Hz} / \mathrm{s}$ ), slope from the maximum $f_{0}$ to the end of the call (slope $\mathrm{M}-\mathrm{E} ; \mathrm{Hz} / \mathrm{s}$ ), inflection rate (number of frequency 


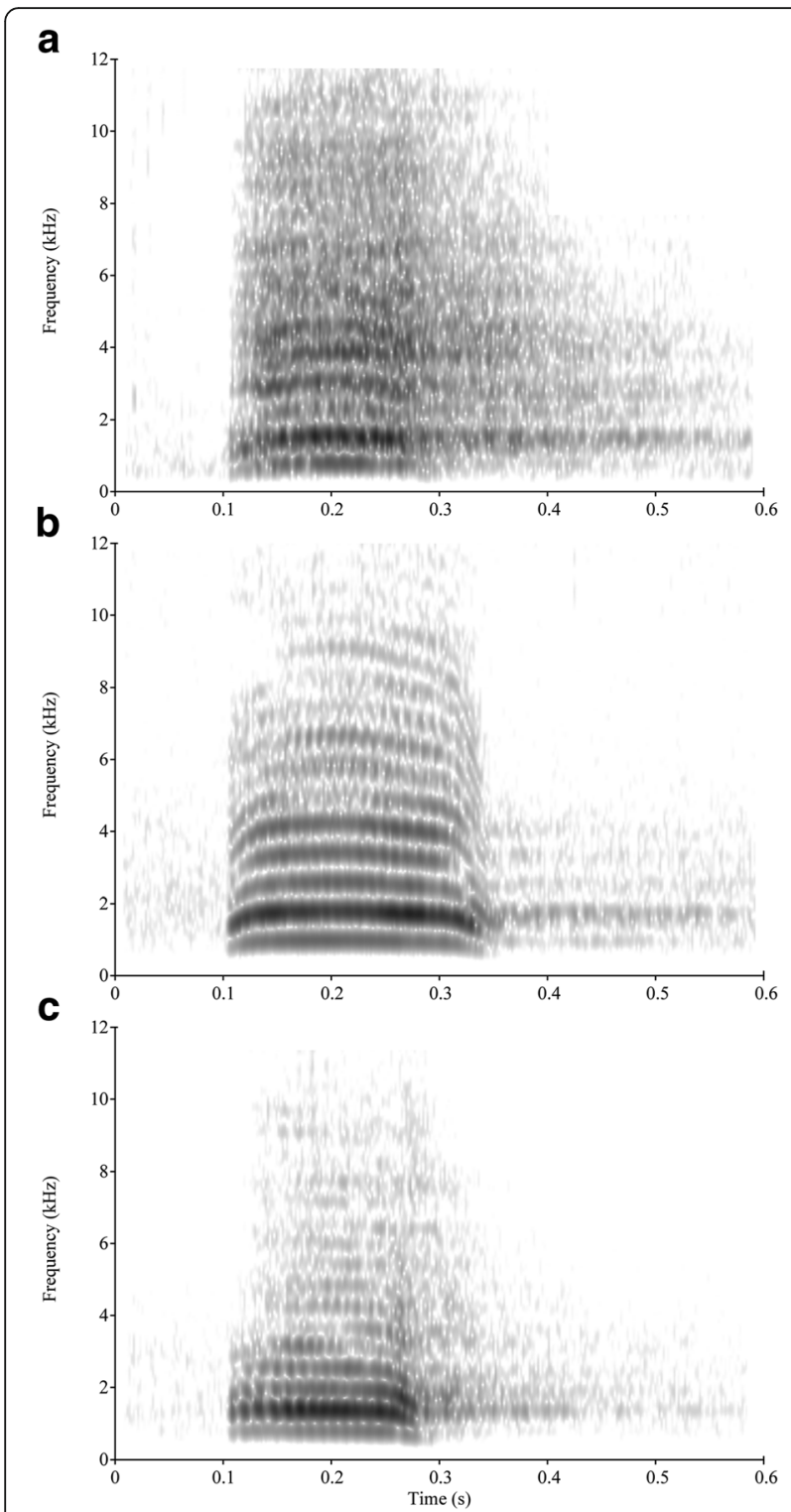

Fig. 1 Spectrogram of a food call of (a) a juvenile, (b) a subadult, and (c) an adult common raven (FFT method, window length $=0.01$, time step $=0.002$, frequency step $=20$, Gaussian shape)

changes/s), harmonicity (HNR; dB), jitter (the absolute fo difference between consecutive $f o$ measurements/the average period), fo variation (sum of all $f_{0}$ changes measured/ call duration; $\mathrm{Hz}$ ), amplitude range (maximum $\mathrm{dB}-$ minimum $\mathrm{dB}$ ) and amplitude modulation (AM). All amplitude related measurements are independent of recording distance as they are relative measures within a call. Mean values of relevant call characteristics within age categories and sexes are listed in Table 1.

\section{Statistical analysis}

A Principal Component Analysis (PCA) was conducted to reduce the amount of acoustic variables after partially correlated variables were removed. Three Principal Components (PCs) were extracted with an eigenvalue greater than 1.0 using a varimax rotation.

Three linear mixed-effect models (LMMs) were calculated using the PC scores as response variables. Individual identity was entered as a random effect to account for repeated sampling. As potential fixed effects, sex, age-class, and weight at trapping were tested for multicollinearity by calculating Variance Inflation Factors (VIF) [48]. Sex and weight showed high collinearity, and thus weight was investigated separately using nonparametric Spearman rank correlations. As fixed effects in the LMMs, sex and age-class were used. For model selection (Table 2) models were ranked by their differences in AICc $(\triangle \mathrm{AICc})$, that were calculated by subtracting the lowest AICc from all other AICc values. The relative likelihoods (exp $(-0.5 / \Delta \mathrm{AICc}))$ and Akaike weights (relative likelihood/sum of all relative likelihoods) were computed as measures of strength of evidence for each model [49]. When several models had high support $(\Delta \mathrm{i} \leq 2)$, model averaging was conducted (Table 3). In order to obtain all coefficients in the comparision between juveniles, subadults and adults we changed the reference category an reran the models. Estimated mean values, $\mathrm{z}$ and $p$ values were obtained from the averaged models for all coefficients.

Statistical analysis was performed in R Version 3.3.3 [50] using the packages GPA rotation (version 2014.11-1 [51]), psych (version 1.7.3.21 [52]), AICcmodavg [53], MuMIn (version 1.15.6 [54]), and lme4 (version 1.1-13 [55]). Estimated values, confidence intervals (CI) as well as $\mathrm{z}$ - and $p$-values were calculated with functions in the package MuMIn (version 1.15.6 [54]).

\section{Results}

Principle component analysis resulted in three factors. The three PCs explained $81 \%$ of the overall variance. Measures of $f_{\mathrm{o}}$ (mean $f_{\mathrm{o}}$, maximum $f_{\mathrm{o}}$, start and mid $f_{\mathrm{o}}$ ) loaded on the first PC and explained $41 \%$ of the variance. PC2 contained the acoustic variables call duration, HNR, and jitter, and contributed $27 \%$ to the overall variance. Amplitude-related vocal parameters (amplitude modulation and amplitude range) loaded on the third PC and explained $14 \%$ of the variance. The standardized loadings are shown in Table 2. PC scores were extracted for further analyses.

Model selection procedure revealed that in PC1 the nullmodel as well as the model including sex explains most of the variance (Table 4); in PC2 and PC3 the models with either age-class alone or with sex and age-class explained the variance the best. Scores of PC2 were highest in juveniles and decreased in subadults, and were lowest adults (Table 3, Fig. 2a). Scores of PC3 were also found to be highest in juveniles and lower in subadults, but higher in adults as 
Table 1 Mean values and standard errors (SE) of acoustic variables used in the PCA

\begin{tabular}{|c|c|c|c|c|c|c|}
\hline & Juvenile & & Subadult & & Adult & \\
\hline & Female $(N=43 ; 2)$ & Male $(N=6 ; 1)$ & Female $(N=137 ; 5)$ & Male $(N=27 ; 2)$ & Female $(N=198 ; 6)$ & Male $(N=7,1)$ \\
\hline & Mean $\pm S E$ & Mean \pm SE & Mean \pm SE & Mean \pm SE & Mean \pm SE & Mean \pm SE \\
\hline Mean $f \circ(\mathrm{Hz})$ & $755.053 \pm 15.527$ & $774.468 \pm 3.277$ & $679.941 \pm 7.605$ & $715.327 \pm 6.215$ & $643.749 \pm 3.196$ & $598.14 \pm 2.421$ \\
\hline Maximum fo $(\mathrm{Hz})$ & $809.845 \pm 12.933$ & $827.117 \pm 4.627$ & $709.005 \pm 7.953$ & $755.367 \pm 6.373$ & $671.995 \pm 3.523$ & $619.023 \pm 3.119$ \\
\hline Start fo $(\mathrm{Hz})$ & $658.953 \pm 17.434$ & $647.698 \pm 9.471$ & $640.394 \pm 7.155$ & $626.777 \pm 8.569$ & $595.298 \pm 2.976$ & $578.75 \pm 6.946$ \\
\hline Mid fo $(\mathrm{Hz})$ & $793.836 \pm 16.825$ & $823.3 \pm 4.254$ & $702.317 \pm 8.131$ & $751.162 \pm 6.753$ & $666.727 \pm 3.674$ & $616.813 \pm 3.018$ \\
\hline Call duration (s) & $0.299 \pm 0.014$ & $0.237 \pm 0.006$ & $0.217 \pm 0.003$ & $0.226 \pm 0.004$ & $0.201 \pm 0.002$ & $0.2 \pm 0.003$ \\
\hline HNR (dB) & $10.587 \pm 0.788$ & $19.338 \pm 0.228$ & $13.916 \pm 0.279$ & $15.819 \pm 0.549$ & $16.055 \pm 0.186$ & $21.36 \pm 0.296$ \\
\hline Jitter & $0.035 \pm 0.003$ & $0.01 \pm 0$ & $0.014 \pm 0.001$ & $0.013 \pm 0.001$ & $0.011 \pm 0$ & $0.01 \pm 0$ \\
\hline Amplitude modulation & $32.034 \pm 1.436$ & $30.058 \pm 2.225$ & $39.325 \pm 1.919$ & $30.413 \pm 1.235$ & $30.921 \pm 0.773$ & $30.579 \pm 2.221$ \\
\hline Amplitude range $(\mathrm{dB})$ & $9.422 \pm 0.553$ & $9.352 \pm 0.656$ & $8.724 \pm 0.397$ & $10.51 \pm 1.008$ & $8.615 \pm 0.213$ & $12.571 \pm 1.116$ \\
\hline
\end{tabular}

$\mathrm{N}$ denotes the number of calls analysed; and the number of individuals per age-class and sex. Five individuals were sampled in two age-classes

compared to subadult individuals (Table 4, Fig. 2a). Sex did not show a strong influence on the regression scores of PC2 and PC3 (cp. Fig. 2b). Scores of PC1 did not vary with age-class or sex (Table 4, Fig. 2a and b).

There was no significant correlation between weight and the scores of PC1 (Spearman rank correlation: $\mathrm{rs}=$ -0.021, $p=0.9562$ ), PC2 ( $\mathrm{rs}=-1.175, p=0.5883$ ), and PC3 ( $\mathrm{rs}=0.538, p=0.0749)$.

\section{Discussion}

We here showed that food-associated 'haa' calls of ravens disclose sex- and age-related characteristics about the

Table 2 Model selection for the LMMs investigating the effects of sex and age-class on for the three Principle Components (PC1-PC3)

\begin{tabular}{lllll}
\hline Models & AlCc & $\Delta i$ & Relative likelihood & Akaike weight \\
\hline PC1 & & & & \\
Sex + Age-class & 614.59 & 4.80 & 0.091 & 0.053 \\
Sex & $\mathbf{6 1 1 . 6 7}$ & $\mathbf{1 . 8 9}$ & $\mathbf{0 . 3 8 8}$ & $\mathbf{0 . 2 2 7}$ \\
Age-class & 612.69 & 2.91 & 0.234 & 0.137 \\
Null & $\mathbf{6 0 9 . 7 8}$ & $\mathbf{0 . 0 0}$ & $\mathbf{1 . 0 0 0}$ & $\mathbf{0 . 5 8 4}$ \\
PC2 & & & & \\
Sex+Age-class & $\mathbf{6 3 7 . 8 1}$ & $\mathbf{1 . 6 9}$ & $\mathbf{0 . 4 2 9}$ & $\mathbf{0 . 3 0 0}$ \\
Sex & 652.81 & 16.69 & 0.000 & 0.000 \\
Age-class & $\mathbf{6 3 6 . 1 2}$ & $\mathbf{0 . 0 0}$ & $\mathbf{1 . 0 0 0}$ & $\mathbf{0 . 6 9 9}$ \\
Null & 650.96 & 14.84 & 0.001 & 0.000 \\
PC3 & & & & \\
Sex+ Age-class & $\mathbf{1 0 7 6 . 3 2}$ & $\mathbf{1 . 0 4}$ & $\mathbf{0 . 5 9 5}$ & $\mathbf{0 . 3 7 3}$ \\
Sex & 1116.96 & 41.68 & 0.000 & 0.000 \\
Age-class & $\mathbf{1 0 7 5 . 2 9}$ & $\mathbf{0 . 0 0}$ & $\mathbf{1 . 0 0 0}$ & $\mathbf{0 . 6 2 7}$ \\
Null & 1118.62 & 43.34 & 0.000 & 0.000 \\
\hline
\end{tabular}

Corrected Akaike Information Criterion (AICc) values, their differences $(\Delta \mathrm{i})$, the relative likelihood, and the resulting Akaike weights are shown for each model. Models with highest support $(\Delta \mathrm{i} \leqq 2)$ are indicated in bold type phenotype of the caller. These results support the idea of class-specific cues in acoustic signals that would enable class-level recognition [1], i.e. that naïve ravens listening to 'haa' calls may extract information about the age-class and the sex of the callers.

Differentiating unknown callers in a social system with high degrees of fission-fusion helps in decision-making processes, when individual recognition is not possible based on missing knowledge on about others. In ravens, vast numbers of individuals gather for roosting [56-58] and feeding [30, 31, 37, 38, 41]. The numbers of individuals within a group fluctuate throughout the year while the stratification of the group based on relationship qualities according to sex, age, and kinship stays consistent $[43,59,60]$. These constantly changing groups impose high demands and challenges on each individual when evaluating collaborative and competitive interests for large numbers of conspecifics. Common ravens show collaborations in feeding situations via recruitment [40, 56-58] but at the same time compete for resources. As aggression during foraging in ravens is relatively high, and fights could cause costly injuries, decisions about whether to join or avoid a feeding situation can be crucial. By assessing acoustic cues about sex and age, the relative strength and reliability of unknown 'haa' callers are conveyed in addition to food-availability [30, 38, 40, 41].

The reliability of recruitment to food in ravens increases with age [37], and thus perceivers might be able to assess signal reliability based on callers' age. The ability of perceivers to selectively respond to specific classes has been reported for instance in alarm calls of marmots (Marmota flaviventris) where juvenile calls elicit more attention [61], and in vervet monkey calls (Cercopithecus aethiops), where the reliability of the signaller was learned in a playback study [62]. Caller reliability appears highly crucial for the evolution and maintenance of alarm call and food call communication [63]. Additionally, juvenile 
Table 3 Averaged LMMs investigating the effects of sex and age-class onto the three Principal Components (PC1-PC3), with coefficients, estimated means (EM), standard error (SE), z values, significances (p), and lower and upper confidence intervals (Cl)

\begin{tabular}{|c|c|c|c|c|c|c|}
\hline Coefficients & EM & SE & $z$ value & $p$ & $2.5 \% \mathrm{Cl}$ & $97.5 \% \mathrm{Cl}$ \\
\hline \multicolumn{7}{|l|}{$\overline{P C 1}$} \\
\hline (Intercept) & -0.18 & 0.29 & 0.62 & 0.537 & -0.74 & 0.39 \\
\hline $\operatorname{Sex}^{\mathrm{a}}$ (female vs. male) & 0.24 & 0.63 & 0.38 & 0.701 & -0.99 & 1.48 \\
\hline \multicolumn{7}{|l|}{ PC2 } \\
\hline (Intercept) & 0.51 & 0.34 & 1.48 & 0.1380 & -0.16 & 1.19 \\
\hline Sex (female vs. male) & -0.43 & 0.71 & 0.61 & 0.5424 & -1.81 & 0.95 \\
\hline Age-class $^{\mathrm{b}}$ (juvenile vs. subadult) & -0.06 & 0.12 & 0.50 & 0.6195 & -0.29 & 0.17 \\
\hline Age-class ${ }^{\text {b }}$ (juvenile vs. adult) & -0.43 & 0.14 & 2.96 & 0.0031 & -0.71 & -0.14 \\
\hline Age-class $^{c}$ (subadult vs. adult) & -0.37 & 0.08 & 4.37 & $<0.0001$ & -0.53 & -0.20 \\
\hline \multicolumn{7}{|l|}{$\mathrm{PC} 3$} \\
\hline (Intercept) & 1.40 & 0.34 & 4.11 & 0.0000 & 0.73 & 2.07 \\
\hline Sex (female vs. male) & 0.62 & 0.60 & 1.03 & 0.3021 & -0.55 & 1.78 \\
\hline Age-class ${ }^{\text {b }}$ (juvenile vs. subadult) & -0.76 & 0.20 & 3.80 & 0.0001 & -1.15 & -0.37 \\
\hline Age-class $^{\mathrm{b}}$ (juvenile vs. adult) & -1.63 & 0.24 & 6.77 & $<0.0001$ & -2.10 & -1.16 \\
\hline Age-class $^{\complement}$ (subadult vs. adult) & -0.87 & 0.14 & 6.16 & $<0.0001$ & -1.15 & -0.60 \\
\hline
\end{tabular}

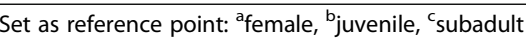

senders of food-associated calls might profit from indicating their age to unknown conspecifics. As juvenile foodassociated calls (also termed 'chii calls') are supposed to derive from begging calls [40], these calls may indicate parents about the hunger level of their offspring [40] and might function as puppy licence. Thus, perceivers of these calls might take into account that parent ravens could be in the vicinity and defend their young.

It is noteworthy that, compared to females, males tend to show low rates of food-associated calls [31]. In a previous experiment, where raven food-associated calls were played back in the wild, nine out of ten birds responded to females [30]. As females are in general lower in rank [64], especially higher ranking males might profit

Table 4 Component matrix of the PCA with loadings of each acoustic variable

\begin{tabular}{llll}
\hline Acoustic Variable & \multicolumn{3}{l}{ Principal Components } \\
\cline { 2 - 4 } & 1 & 2 & 3 \\
\hline Mean fo & $\mathbf{0 . 9 9}$ & 0.08 & -0.03 \\
Maximum fo & $\mathbf{0 . 9 7}$ & 0.18 & 0.00 \\
Start fo & $\mathbf{0 . 8 4}$ & -0.14 & -0.16 \\
Mid fo & $\mathbf{0 . 9 7}$ & 0.12 & 0.00 \\
Call duration & 0.23 & $\mathbf{0 . 8 7}$ & -0.03 \\
HNR & 0.10 & $-\mathbf{0 . 8 0}$ & 0.36 \\
Jitter & 0.04 & $\mathbf{0 . 9 4}$ & 0.03 \\
Amplitude modulation & -0.03 & 0.14 & $\mathbf{0 . 7 0}$ \\
Amplitude range & -0.16 & -0.01 & $\mathbf{0 . 8 1}$ \\
\hline
\end{tabular}

The dimension of the acoustic variables was reduced to three Principal Components $(\mathrm{KMO}=0.73)$. Interpretable factor loadings are indicated in bold from approaching food-calling females. A similar effect was found in brown capuchin monkeys (Cebus apella), where lower-ranking females call more than higherranking individuals [65]. Additionally, low-ranking ravens might benefit from attracting other non-breeders especially when calling within a territory of a breeding raven pair. By increasing the number of non-breeders and thus overpowering the territorial pair, food accessibility might be secured. Furthermore, dominant male callers may use another food-related call ('who'; [37]). This call type might indicate different phenotypic information than the here presented 'haa' calls.

PC1, which combined acoustic variables related to $f_{0}$, showed least evidence for explaining sex and age-class related differences. Still, differences in PC1 do exist and were previously related to individual recognition [33]. They could be size dependent, as after fledging and gaining weight, developmental changes of internal structures like ossification of tracheal and syringeal cartilaginous rings take place, and thus can cause changes in $f_{0}$ due to anatomical changes of the syrinx like size post-fledging [66]. Additionally, neural changes due to the ontogenetic development of the caller might correlate with our classification of age-classes that potentially relate to individuality. Neural changes, like increases of the HVC after sexual maturing [67], might be reflected in differences of $f$ o.

Furthermore, deterministic chaos, which is reflected in HNR of a call, was included in PC2. It is important in the acoustic communication of animals $[68,69]$ as it can signal urgency or motivation (e.g. baby cries [70], monkey alarm calls [71]), and might be perceived by listening 


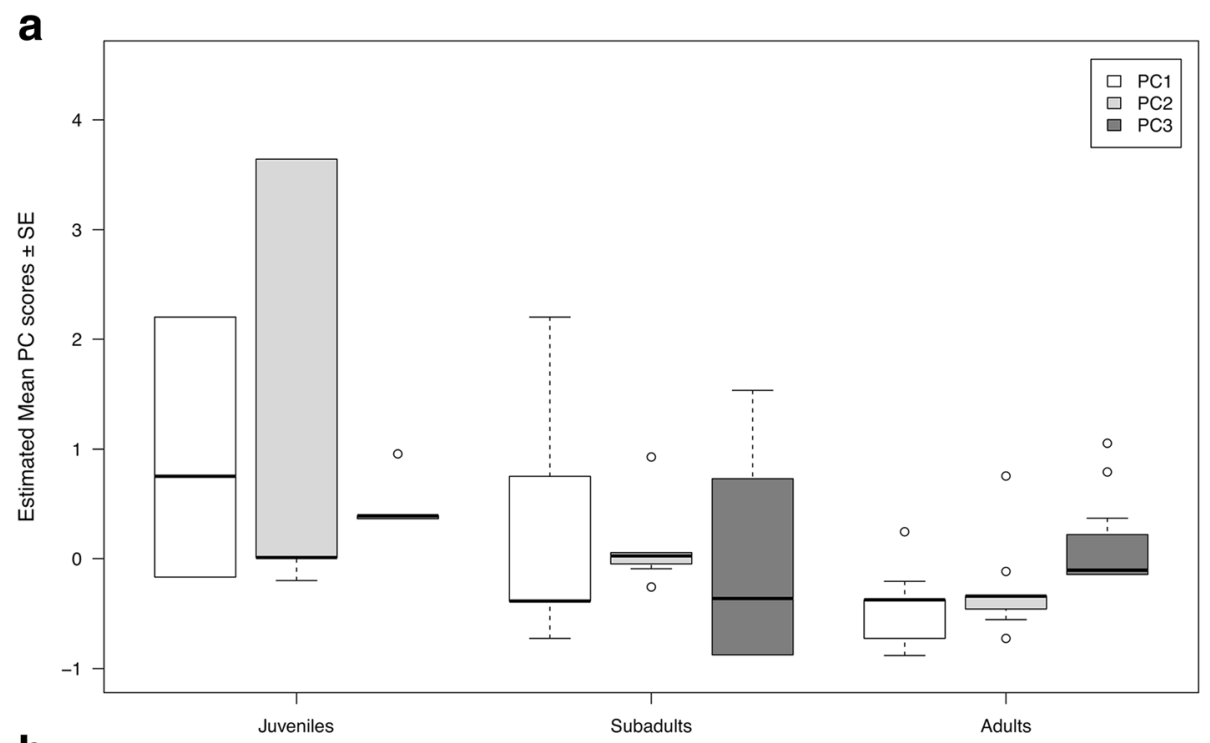

b

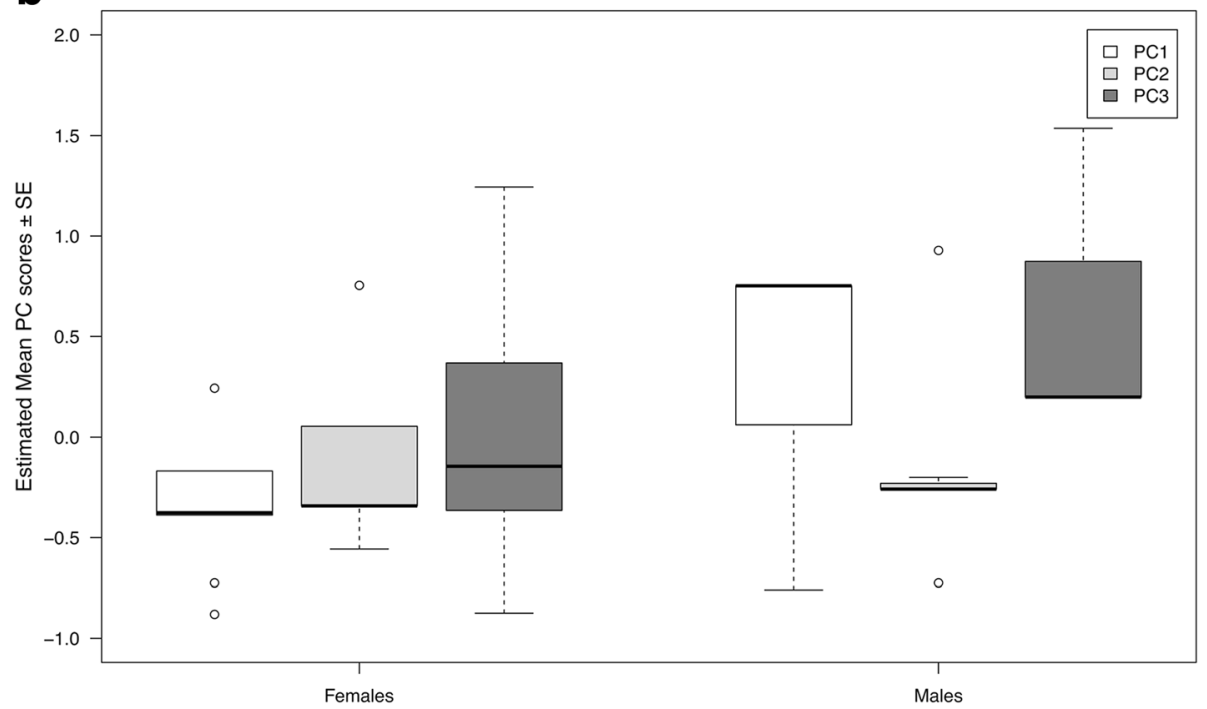

Fig. 2 Estimated means \pm standard errors (SE) of the three PCs for different age-classes (a), and for male and female common ravens (b). PC1 summarizes acoustic properties related to the fundamental frequency of "haa" calls, PC2 includes call duration and source-related acoustic features, and PC3 amplitude-related measures

individuals (e.g.: [72, 73]). In relation to the ontogenetic development of the individual we expect a decrease of urgency-related features in 'haa'-calls that might also relate to the motivation [8] i.e. hunger level of the caller. In congruence with this motivation-structural rule, foo$\mathrm{d}$-associated calls are hypothesized to develop from begging calls [40]. In addition to HNR also jitter is included in PC2. Mammals are known to increase jitter based on changes of oestrogen in females [19, 74] and of testosterone in males [19, 75]. Similar mechanisms based on hormonal changes could be at play in raven 'haa' calls that might relate to urgency of the callers. Similarly, call duration is represented in PC2 and is often related to urgency [76]. Highest levels are found in juvenile females bearing the lowest rank in raven societies and thus might encounter high levels of constrains in gaining access to food [64].

Amplitude modulation is mainly represented in PC3 and varies according to age-class. We suggest that similar to deterministic chaos, jitter, and call duration, an increase of amplitude modulation is related to urgency. Still, amplitude modulation has not been considered in many animals and was considered as low hierarchy parameter, i.e. transmitting little information [77].

As male ravens are in general larger than females, gross body mass and size differences [28] might correlate with differences in syringeal structures, and cause sexually dimorphic acoustic features of raven calls. Such size-related differences have been reported for jungle crows [22] and 
other bird species like murres [78], while to our knowledge no such differences were reported in the literature for ravens, yet. Despite this effect, it has been discussed that based on small effect sizes, fo differences have a low reliability as indicators of body size in birds [79]. Hence, fo variances might not be good indicators for the sex of the calling raven when sex differences are merely based on size-dependent differences in syringeal anatomy. Note that the weight of the studied individuals did not correlate with either of the PCs, confirming previously shown small effect sizes.

Similarly, differences in hormone levels between male and female birds can cause variation in calling behaviour [80] and activity in the neural song control regions [81]. While hormonal changes have been shown to affect the vibrational properties of sound-producing structures in mammals [74] to our knowledge such an effect has not been documented for birds. Especially bird species with monomorphic singing and calling behaviour are less studied [82] in their differences in higher vocal centre (HVC) structures. Still, sexually dimorphic neural structures might cause sexually dimorphic calls in ravens, which has to be studied in more detail.

Measures of amplitude modulation and range cluster in PC3 and relate to age-classes. While most of the measures decrease or increase with age, amplitude-related parameters are lower in subadults than in adults. This effect also is in contrast to reduced variation in all parameters with increasing age (see Table 3) and might be connected to morphological changes during maturation. Age classification of 'haa' calls is strongly supported by our data, especially based on acoustic variables in PC2 and PC3. We hypothesize that labial flexibility, mass, and length, which have been shown to vary with age in mammals [83], might change as signallers mature. Structural differences of the vocalizing apparatus in turn determine acoustic features of a vocalization (e.g. [83]). In addition to variations in the vocal organ, maturation of neural structures based on testosterone-induced growth of the HVC [84] might additionally influence acoustic features of raven calls, as was shown in birdsong [85].

\section{Conclusion}

Taken together, we herewith show that raven 'haa' calls vary according to sex and age of the vocalizer and might be the underlying mechanism of class-level recognition. Especially in food-related calls that are recruiting conspecifics to potentially dangerous feeding situations, class-level recognition could help when encountering unknown individuals while individual recognition is used during repeated interactions with already known individuals. Thus, ravens with a pronounced level of fission-fusion seem to possibly make use of class-level recognition as well as individual recognition during their complex feeding behaviour.

\section{Funding}

This work was funded by EUROCORES_TECT: Cooperation in Corvids (I 105-G11) and FWF-Start: 'Raven Politics' (START: Y-366-B17).

\section{Availability of data and materials}

The datasets used and/or analysed during the current study are available from the corresponding author on reasonable request.

\section{Authors' contributions}

Conceived and designed the project: MB, GS, TB. Performed the survey: MB, GS. Analyzed the data: MB, GS. Contributed materials/analysis tools: MB, GS TB. Wrote the paper: MB, GS, TB. All authors read and approved the final manuscript.

Ethics approval and consent to participate

All studies are in compliance with legal regulations. Austrian ministry granted animal keeping permission BMWFW-66.006/0011-WF/II/3b/2014 as well as animal testing BMWF-66.006/0009-II/3b/2012; BMWFW-66.006/0019-WF/II/3b/2014. All experiments adhere to the ethical guidelines for animal behaviour research from developed by the Association for the Study of Animal Behaviour.

Consent for publication

Not applicable.

\section{Competing interests}

The authors declare that they have no competing interests.

\section{Publisher's Note}

Springer Nature remains neutral with regard to jurisdictional claims in published maps and institutional affiliations.

\section{Author details}

${ }^{1}$ Department of Cognitive Biology, University of Vienna, Vienna, Austria. ${ }^{2}$ Konrad Lorenz Forschungsstelle, Core Facility, University of Vienna, Gruenau im Almtal, Austria. ${ }^{3}$ Department of Psychology, University of Cambridge, Cambridge, UK.

Received: 6 April 2017 Accepted: 6 February 2018

Published online: 13 March 2018

References

1. Tibbetts E, Dale J. Individual recognition: it is good to be different. Trends Ecol Evol. 2007;22:529-37.

2. Bradbury JW, Vehrencamp SL. Principles of animal communication. Sunderland: Sinauer Associates; 2011.

3. Falls JB. Individual recognition by sounds in birds. Acoust Commun Birds. 1982;2:237-78.

4. Trivers R. The evolution of reciprocal altruism. Q Rev Biol. 1971;46:35.

5. Aureli F, Schaffner Colleen M, Boesch C, Bearder Simon K, Call J, Chapman Colin A, Connor R, Fiore Anthony D, Dunbar Robin IM, Henzi SP, et al. Fission-fusion dynamics: new research frameworks. Curr Anthropol. 2008;49: $627-54$

6. Sayigh LS, Tyack PL, Wells RS, Scott MD, Irvine AB. Sex difference in signature whistle production of free-ranging bottlenose dolphins, Tursiops truncates. Behav Ecol Sociobiol. 1995;36:171-7.

7. Green SM. Sex differences and age gradations in vocalizations of Japanese and lion-tailed monkeys (Macaca fuscata and Macaca silenus). Am Zool. 1981:21:165-83.

8. Morton ES. On the occurrence and significance of motivation-structural rules in some bird and mammal sounds. Am Nat. 1977;111:855-69.

9. Clark AP. Rank differences in the production of vocalizations by wild chimpanzees as a function of social context. Am J Primatol. 1993;31:159-79.

10. Pipitone RN, Gallup GG Jr. Women's voice attractiveness varies across the menstrual cycle. Evol Hum Behav. 2008;29:268-74.

11. Fant G. Acoustic Theory of Speech Production. Revised edition (January 1970) edn. The Hague: Mouton \& Co. N.V; 1960. 
12. Elemans $C$, Rasmussen $J H$, Herbst $C T$, Düring DN, Zollinger SA, Brumm H, Srivastava K, Svane N, Ding M, Larsen ON. Universal mechanisms of sound production and control in birds and mammals. Nat Commun. 2015;6:8978.

13. Fitch WT. Vocal tract length and formant frequency dispersion correlate with body size in rhesus macaques. J Acoust Soc Am. 1997;102:1213-22.

14. Story BH, Titze IR, Hoffman EA. Vocal tract area functions for an adult female speaker based on volumetric imaging. J Acoust Soc Am. 1998;104:471-87.

15. Beckers $G$, Nelson B, Suthers R. Vocal-tract filtering by lingual articulation in a parrot. Curr Biol. 2004;14:1592-7.

16. Nowicki S. Vocal tract resonances in oscine bird sound production: evidence from birdsongs in a helium atmosphere. Nature. 1987;325:53-5.

17. Fitch WT, Kelley J. Perception of vocal tract resonances by whooping cranes Grus americana. Ethology. 2000;106:559-74.

18. Patterson DK, Pepperberg IM. A comparative study of human and parrot phonation: acoustic and articulatory correlates of vowels. J Acoust Soc Am. 1994;96:634-48.

19. Charlton B, Zhihe Z, Snyder R. The information content of giant panda, Ailuropoda melanoleuca, bleats: acoustic cues to sex, age and size. Anim Behav. 2009;78:893-8.

20. Gingras B, Boeckle M, Herbst CT, Fitch WT. Call acoustics reflect body size across four genera of anurans. J Zool. 2013;289:143-50.

21. Chamberlain DR, Gross WB, Cornwell GW, Mosby HS. Syringeal anatomy in the common crow. Auk. 1968:85:244.

22. Tsukahara N, Aoyama M, Sugita S. Sexual differences in the vocalizations and vocal organs of the jungle crow Corvus macrorhynchos. Japanese J Ornithology. 2006;55:7-17.

23. Tsukahara N, Kamata N, Nagasawa M, Sugita S. Bilateral innervation of syringeal muscles by the hypoglossal nucleus in the jungle crow (Corvus macrorhynchos). J Anat. 2009;215:141-9.

24. Tsukahara N, Yang Q, Sugita S. Structure of the syringeal muscles in jungle crow (Corvus macrorhynchos). Anat Sci Int. 2008;83:152-8.

25. Bock WJ. Morphology of the larynx of Corvus Brachyrhynchos (Passseriformes Corvidae). Wilson Bulletin. 1978;90:553-65.

26. Wallschläger D. Correlation of song frequency and body weight in passerine birds. Cell Mol Life Sci. 1980;36:412.

27. Yorzinski J, Vehrencamp S, Clark A, McGowan K. The inflected alarm caw of the american crow: differences in acoustic structure among individuals and sexes. Condor. 2006:108:518-29.

28. dos Anjos L, Debus SJS, Madge SC, Marzluff JM. Family Corvidae (crows). In: del Hoyo J, Elliott A, Christie DA, editors. Handbook of the birds of the world. Volume 14. Bacelona: Lynx Edicions; 2009. p. 494-640.

29. Bedrosian B, Loutsch J, Craighead D. Using Morphometrics to determine the sex of common ravens. Northwest Nat. 2008;89:46-52.

30. Szipl G, Boeckle M, Wascher CA, Spreafico M, Bugnyar T. With whom to dine? Ravens' responses to food-associated calls depend on individual characteristics of the caller. Anim Behav. 2015;99:33-42.

31. Szipl G, Bugnyar T. Craving ravens: individual 'haa' call rates at feeding sites as cues to personality and levels of fission-fusion dynamics? Anim Behav Cognit. 2014;1:265-80

32. Boeckle M, Bugnyar T. Long-term memory for affiliates in ravens. Curr Biol. 2012;22:801-6

33. Boeckle M, Szipl G, Bugnyar T. Who wants food? Individual characteristics in raven yells. Anim Behav. 2012:84:1123-30.

34. Loretto M-C, Reimann S, Schuster R, Graulich DM, Bugnyar T. Shared space, individually used: spatial behaviour of non-breeding ravens (Corvus corax) close to a permanent anthropogenic food resource. J Ornithol. 2016;157: 339-450.

35. Loretto M-C, Schuster R, Bugnyar T. GPS tracking of non-breeding ravens reveals the importance of anthropogenic food sources during their dispersal in the eastern alps. Curr Zool. 2016;62:337-44.

36. Loretto M-C, Schuster R, Itty C, Marchand P, Genero F, Bugnyar T. Fission-fusion dynamics over large distances in raven non-breeders. Sci Rep. 2017;7:380.

37. Bugnyar $T$, Kijne $M$, Kotrschal $K$. Food calling in ravens: are yells referential signals? Anim Behav. 2001;61:949-58.

38. Bugnyar T, Kotrschal K. Movement coordination and signalling in ravens (Corvus corax): an experimental field study. Acta Ethologica. 2001;3:101-9.

39. Heinrich B. Winter foraging at carcasses by the three sympatric corvids, with emphasis on recruitment by the raven, Corvus corax. Behav Ecol Sociobiol. 1988;23:141-56

40. Heinrich B, Marzluff J. Do common ravens yell because they want to attract others? Behav Ecol Sociobiol. 1991;28:13-21.
41. Marzluff J, Heinrich B. Foraging by common ravens in the presence and absence of territory holders: an experimental analysis of social foraging. Anim Behav. 1991;42:755-70.

42. Drack G, Kotrschal K. Aktivitätsmuster und Spiel freilebender Kolkraben Corvus corax in inneren Almtal/Oberösterreich. Monicula. 1995;7:159-74.

43. Braun A, Walsdorff T, Fraser ON, Bugnyar T. Socialized sub-groups in a temporary stable raven flock? J Ornithol. 2012;153(1):97-104.

44. Heinrich B, Marzluff J. Age and mouth color in common ravens. Condor. 1992:94:549-50.

45. Heinrich B. When is the common raven black? Wilson Bull. 1994;106:571-2.

46. Boersma P, Weenik D: PRAAT: Doing phonetics by computer (version 5.2.10) [computer program], retrieved from http://www.praat.org/ (Last Viewed 01/ 2011). 2011.

47. Titze IR, Baken RJ, Bozeman KW, Granqvist S, Henrich N, Herbst CT, Howard DM, Hunter EJ, Kaelin D, Kent RD, et al. Toward a consensus on symbolic notation of harmonics, resonances, and formants in vocalization. J Acoust Soc Am. 2015:137:3005-7.

48. Zuur AF, leno EN, Elphick CS. A protocol for data exploration to avoid common statistical problems. Methods Ecol Evol. 2009:1:3-14.

49. Burnham KP, Anderson DR, Huyvaert KP. AIC model selection and multimodel inference in behavioral ecology: some background, observations, and comparisons. Behav Ecol Sociobiol. 2011;65:23-35.

50. Team RC. R: a language and environment for statistical computing. Vienna, Austria. URL https://www.r-project.org: R Foundation for Statistical Computing; 2017

51. Bernaards CA, Jennrich RI. Gradient projection algorithms and software for arbitrary rotation criteria in factor analysis. Educ Psychol Meas. 2005;65:676-96.

52. Revelle W. Psych: procedures for personality and psychological research. Evanston, Illinois, USA: Northwestern University; 2017.

53. Mazerolle MJ: AlCcmodavg: model selection and multimodel inference based on (Q)AIC(c). 2017.

54. Bartoń K: MuMln: multi-model inference. R package. 2009.

55. Bates D, Maechler M, Bolker B, Walker S. Fitting linear mixed-effects models using Ime4. J Stat Softw. 2015:67:1-48.

56. Dall S. Can information sharing explain recruitment to food from communa roosts? Behav Ecol. 2002;13:42-51.

57. Marzluff J, Heinrich B. Raven roosts are still information centres. Anim Behav. 2001:61:F14-5.

58. Marzluff J, Heinrich B, Marzluff C. Raven roosts are mobile information centres. Anim Behav. 1996:51:89-103.

59. Fraser O, Aureli F. Reconciliation, consolation and postconflict behavioral specificity in chimpanzees. Am J Primatol. 2008;70:1114-23.

60. Fraser ON, Bugnyar T. The quality of social relationships in ravens. Anim Behav. 2010;79:927-33.

61. Blumstein DT, Daniel JC. Yellow-bellied marmots discriminate between the alarm calls of individuals and are more responsive to calls from juveniles. Anim Behav. 2004:68:1257-65.

62. Cheney DL, Seyfarth RM. Assessment of meaning and the detection of unreliable signals by vervet monkeys. Anim Behav. 1988;36:477-86.

63. Searcy WA, Nowicki S. The evolution of animal communication: reliability and deception in signaling systems. Sunderland: Princeton University Press; 2005.

64. Braun A, Bugnyar T. Social bonds and rank acquisition in raven nonbreeder aggregations. Anim Behav. 2012;84:1507-15.

65. Pollick AS, Gouzoules H, de Waal FBM. Audience effects on food calls in captive brown capuchin monkeys, Cebus Apella. Anim Behav. 2005;70:1273-81.

66. Appel FW. Sex dimorphism in the syrinx of the fowl. J Morphol. 1929;47: 497-517.

67. Nottebohm F, Nottebohm ME, Crane L. Developmental and seasonal changes in canary song and their relation to changes in the anatomy of song-control nuclei. Behav Neural Biol. 1986;46:445-71.

68. Fitch WT, Neubauer J, Herzel H. Calls out of chaos: the adaptive significance of nonlinear phenomena in mammalian vocal production. Anim Behav. 2002;63:407-18

69. Suthers RA, Wild JM, Kaplan G. Mechanisms of song production in the Australian magpie. J Comp Physiol A. 2011;197:45-59.

70. Bell SM, Ainsworth MDS. Infant crying and maternal responsiveness. Child Dev 1972;43(4):1171-90

71. Manser MB, Seyfarth RM, Cheney DL. Suricate alarm calls signal predator class and urgency. Trends Cogn Sci. 2002;6:55-7.

72. Stoeger AS, Baotic A, Li D, Charlton BD. Acoustic features indicate arousal in infant Giant panda Vocalisations. Ethology. 2012;118:896-905. 
73. Manser $M B, B e l l M B$, Fletcher $L B$. The information that receivers extract from alarm calls in suricates. Proc R Soc Lond B Biol Sci. 2001;268:2485-91.

74. Abitbol J, Abitbol P, Abitbol B. Sex hormones and the female voice. J Voice. 1999:13:424-46.

75. Fuchs M, Fröehlich M, Hentschel B, Stuermer IW, Kruse E, Knauft D. Predicting mutational change in the speaking voice of boys. J Voice. 2007; 21:169-78.

76. Briefer E, Aubin T, Rybak F. Response to displaced neighbours in a territorial songbird with a large repertoire. Naturwissenschaften. 2009;96(9):1067-77.

77. Brémond JC, Aubin T. The role of amplitude modulation in distress-call. Ethology Ecol Evol. 1992:4:187-91.

78. Miller EH, Seneviratne SS, Jones IL, Robertson GJ, Wilhelm SI. Syringeal anatomy and allometry in murres (Alcidae: Uria). J Ornithol. 2008;149:545-54

79. Patel R, Mulder RA, Cardoso GC. What makes vocalisation frequency an unreliable signal of body size in birds? A study on black swans. Ethology. 2010;116:554-63

80. Wada M. Effects of sex steroids on calling, locomotor activity, and sexual behavior in castrated male Japanese quail. Horm Behav. 1982;16:147-57.

81. DeVoogd TJ. Steroid interactions with structure and function of avian song control regions. J Neurobiol. 1986;17:177-201.

82. Jawor JM, MacDougall-Shackleton SA. Seasonal and sex-related variation in song control nuclei in a species with near-monomorphic song, the northern cardinal. Neurosci Lett. 2008;443:169-73.

83. Titze I. Principles of voice production. Iowa City IA: National Center for Voice and Speech; 2000.

84. Nottebohm F. Testosterone triggers growth of brain vocal control nuclei in adult female canaries. Brain Res. 1980;189:429-36.

85. Zeigler HP, Marler P. Neuroscience of Birdsong. Sunderland: Cambridge University Press; 2008.

\section{Submit your next manuscript to BioMed Central and we will help you at every step:}

- We accept pre-submission inquiries

- Our selector tool helps you to find the most relevant journal

- We provide round the clock customer support

- Convenient online submission

- Thorough peer review

- Inclusion in PubMed and all major indexing services

- Maximum visibility for your research

Submit your manuscript at www.biomedcentral.com/submit 